\title{
Giant Aneurysmal Bone Cyst of the Anterior Cranial Fossa and Paranasal Sinuses Presenting in Pregnancy: Case Report and Literature Review
}

\author{
Luke Hnenny ${ }^{1} \quad$ Neil Roundy ${ }^{1}$ Victor Zherebitskiy ${ }^{1}$ \\ ${ }^{1}$ Departments of Neurological Surgery, Oregon Health \& Science \\ University, Portland, Oregon, United States \\ 2 Department of Pathology, Oregon Health \& Science University, \\ Portland, Oregon, United States
}

\author{
Marjorie Grafe ${ }^{2}$ Atiya Mansoor ${ }^{2} \quad$ Aclan Dogan ${ }^{1}$
}

J Neurol Surg Rep 2015;76:e216-e221.

\begin{abstract}
Address for correspondence Aclan Dogan, MD, Department of Neurological Surgery, Oregon Health \& Science University, code: CH8N, 3303 SW Bond Avenue, Portland, OR 97239, United States (e-mail: dogana@ohsu.edu).
\end{abstract}

\begin{abstract}
Keywords

- aneurysmal bone cyst

- pregnancy

- skull base

Background and Purpose Aneurysmal bone cysts (ABCs) rarely involve the cranium and have seldom been reported in pregnancy.

Clinical Presentation We describe a case of a 28-year-old woman who presented at 37 weeks of gestation with 3 months of gradually worsening vision, 10 months of proptosis, and restricted ocular motility on the left. Brain imaging revealed a multicystic enhancing mass measuring $5.9 \times 5.3 \times 3.7 \mathrm{~cm}$, centered on the cribriform plate on the left, extending into the anterior cranial fossa superiorly as well as the left nasal cavity, maxillary, sphenoid, and frontal sinuses. Her clinical course is described in detail; 3-month postoperative imaging demonstrated no residual mass.

Conclusion A literature review revealed five previous cases of $A B C s$ associated with pregnancy. We report a rare case of a giant $A B C$ of fibrous dysplasia involving the paranasal sinuses and anterior cranial fossa. We postulate on the possible influence of pregnancy on the clinical course.
\end{abstract}

\section{Introduction}

Jaffe and Lichtenstein provided the first description of an aneurysmal bone cyst $(A B C)$ as a distinct pathologic entity in a series of 19 cases published in $1942 .^{1}$ The most common location was in long bones, and most cases presented between early childhood and adolescence. ${ }^{1}$ Subsequently, these initial observations were confirmed. ${ }^{2}$ A review of 150 patients with $\mathrm{ABC}$ by Mankin et al showed predominant involvement of the tibia, fibula, and femur, and a mean age of 18 years. $^{2}$ Involvement of the skull, however, is rare, representing only 3 to $6 \%$ of all cases. ${ }^{3}$

We report a rare case of a giant $A B C$ arising in the setting of fibrous dysplasia involving the paranasal sinuses and anterior cranial fossa. We also describe details of gross total surgical resection and clinical course. Epidemiology, typical presen- tation, imaging findings, histopathology, treatment options, and clinical outcomes of cranial ABCs are also reviewed. The effect of pregnancy on lesion growth is discussed.

\section{Case Presentation}

\section{History and Examination}

A 28-year-old woman presented at 37 weeks of gestation with 3 months of gradually worsening vision, 10 months of proptosis, and restricted ocular motility on the left. She described onset of left maxillary sinus fullness and pain several months prior to pregnancy and a single episode of epistaxis 2 months prior to presentation. On examination, the patient was found to have anosmia, a left relative afferent papillary defect, lack of light perception, and inability to count fingers with the left eye, a left abducens palsy, received

February 19, 2015 accepted after revision April 19, 2015

published online

September 9, 2015
DOI http://dx.doi.org/ $10.1055 / \mathrm{s}-0035-1555017$. ISSN 2193-6366. (c) 2015 Georg Thieme Verlag KG
Stuttgart · New York

License terms

c) $(1) \$$ 

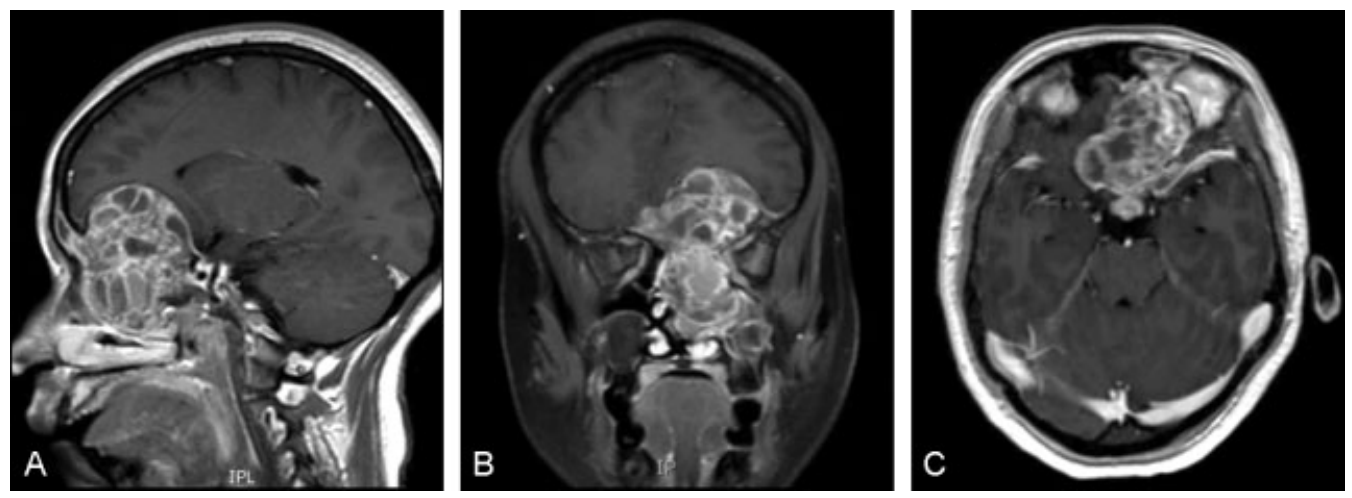

Fig. 1 Preoperative T1 gadolinium-enhanced magnetic resonance imaging demonstrating the lesion of interest. (A) Sagittal. (B) Coronal. (C) Axial. Note the prominent fluid-fluid levels and multiple internal septations.

left-sided epiphora, bilateral nasal obstruction, and significant proptosis of the left eye. Ophthalmologic examination revealed ability to count fingers at 6 inches only in the left eye; visual acuity was 20/25 in the right eye. Visual field testing demonstrated total superior and inferior temporal, superior nasal, and inferior nasal deficits on the left. She underwent an uncomplicated augmented labor with vacuum assistance the day following presentation, resulting in a healthy infant. Further investigations were then initiated.

\section{Magnetic Resonance Imaging}

Brain imaging revealed a multicystic enhancing mass measuring $5.9 \times 5.3 \times 3.7 \mathrm{~cm}$, centered on the cribriform plate on the left, extending into the anterior cranial fossa superiorly as well as the left nasal cavity, maxillary, sphenoid, and frontal sinuses. There were fluid-fluid levels. Mass effect was exerted on the optic nerves and chiasm, as well as the left frontal lobe, with $1 \mathrm{~cm}$ midline shift to the right ( $\mathbf{- F i g . ~ 1 ) . ~}$

\section{Cerebral Angiography}

We performed cerebral angiography to ascertain lesion vascularity for potential preoperative embolization. Interestingly, there was no significant vascular supply to the lesion from either the internal or external carotid circulations. Hence embolization was not performed.

\section{Operation}

The patient underwent bifrontal craniotomy with cranialization of bilateral frontal sinuses and a gross total mass resection. Intraoperatively, the mass was eccentric to the left, primarily involving the cribriform plate and the superomedial aspect of the orbital roof and wall. The mass was completely extradural, and the bone had undergone significant remodeling with lateral displacement of the left orbit. A very thin eggshelllike osseous capsule was carefully dissected from the dura. The mass itself contained several cystic areas containing dark motor oil-like fluid consistent with old blood products. The planum sphenoidale was eroded and elevated, and the bony roof of the optic canal had been replaced.

Attachment of the dura to the crista galli was ligated and divided. The resection extended down through the cribriform plate, the ethmoids, and the maxillary and sphenoid sinuses. The bilateral superior turbinates were resected due to tumor involvement, and the posterior third of the superior nasal septum was also resected due to replacement by the lesion. Upon gross total resection of the mass, the optic chiasm and optic nerves, as well as the sella, had been extradurally skeletonized, and the left orbit had been unroofed medially and superiorly (-Fig. 2).

Reconstruction of the defect was accomplished using a large vascularized pericranial graft harvested at the time of approach. The pericranium was laid back to the origin of the bony defect abutting the location of the anterior clinoids, and it was anchored using 3-mm screws to the lateral sphenoid wings. The bifrontal craniotomy flap was plated and replaced in normal anatomical alignment.

\section{Postoperative Course}

The patient had an uneventful recovery and was discharged on the postoperative day 10 . At the 3-month follow-up, her proptosis had resolved, and vision was 20/25 (right eye) and 20/800 (left eye). Neurologic examination was normal, and the patient reported she was feeling well. Imaging revealed no residual/recurrent tumor (-Fig. 3).

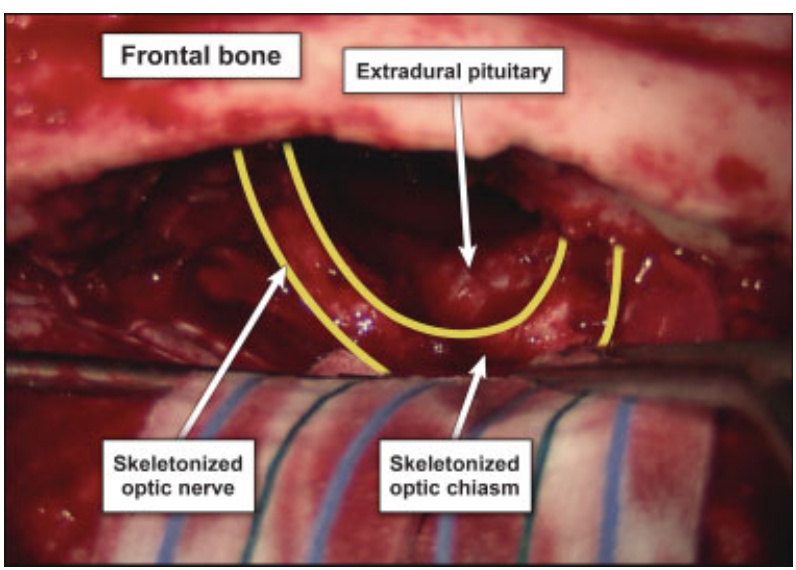

Fig. 2 Intraoperative photograph following complete resection of lesion. 


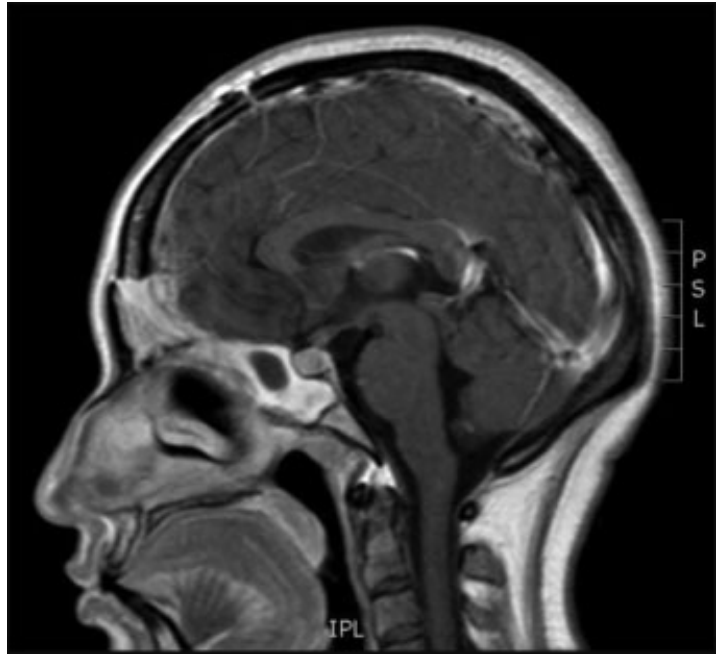

Fig. 3 The 3-month postoperative T1 gadolinium-enhanced magnetic resonance image demonstrating complete resection of lesion.

\section{Pathology}

The resected mass lesion material consisted of multiple fragments of red tan soft tissue with some cartilage and bone. Microscopically ( - Fig. 4), the lesion consisted of multiple blood-filled spaces lined by fibrous septae composed of loose fibrous tissue containing a uniform population of plump fibroblasts admixed with scattered osteoclast-like giant cells. The fibrous septae were rich in capillaries and had foci of chronic inflammatory infiltrates and reactive bone. This histomorphology is characteristic of an $\mathrm{ABC}$. There was a benign fibro-osseous proliferation with irregular curvilinear profiles of the woven bone in the background of the ABC. Osteoblastic rimming was very inconspicuous, putting fibrous dysplasia and ossifying fibroma in the histologic differential diagnosis for the background process. Fragments of unremarkable sinus mucosa accompanied resection material from the left frontal and left maxillary sinuses. Immunohistochemistry for estrogen (ER) and progesterone receptors (PR) did not demonstrate nuclear staining of any cell populations.

\section{Literature Review}

The effect of pregnancy and associated hormonal changes on the growth of $A B C s$ is relatively unknown. Cataltepe et $\mathrm{al}^{4}$ reported a case of an $A B C$ of the frontal bone of a 28 -year-old woman who presented with localized swelling during her first pregnancy. After delivery, the lesion remained quiescent. One year later, she again became pregnant, and during this pregnancy, there was rapid lesion growth. The $A B C$ was resected without complication postdelivery. The authors hypothesize that growth of the ABC during pregnancy may be attributable to increased hematopoietic activity of pregnancy, increased cortisol secretion during pregnancy and its inhibition of normal osteogenesis through vitamin D antagonism, and/or placental secretion of human placental lactogen (HPL), which has a growth hormone-like effect. Westbury et $\mathrm{al}^{5}$ reported a case of a mandibular central giant cell granuloma with $\mathrm{ABC}$ change exhibiting rapid growth during pregnancy. Interestingly, the multinucleated cells of the
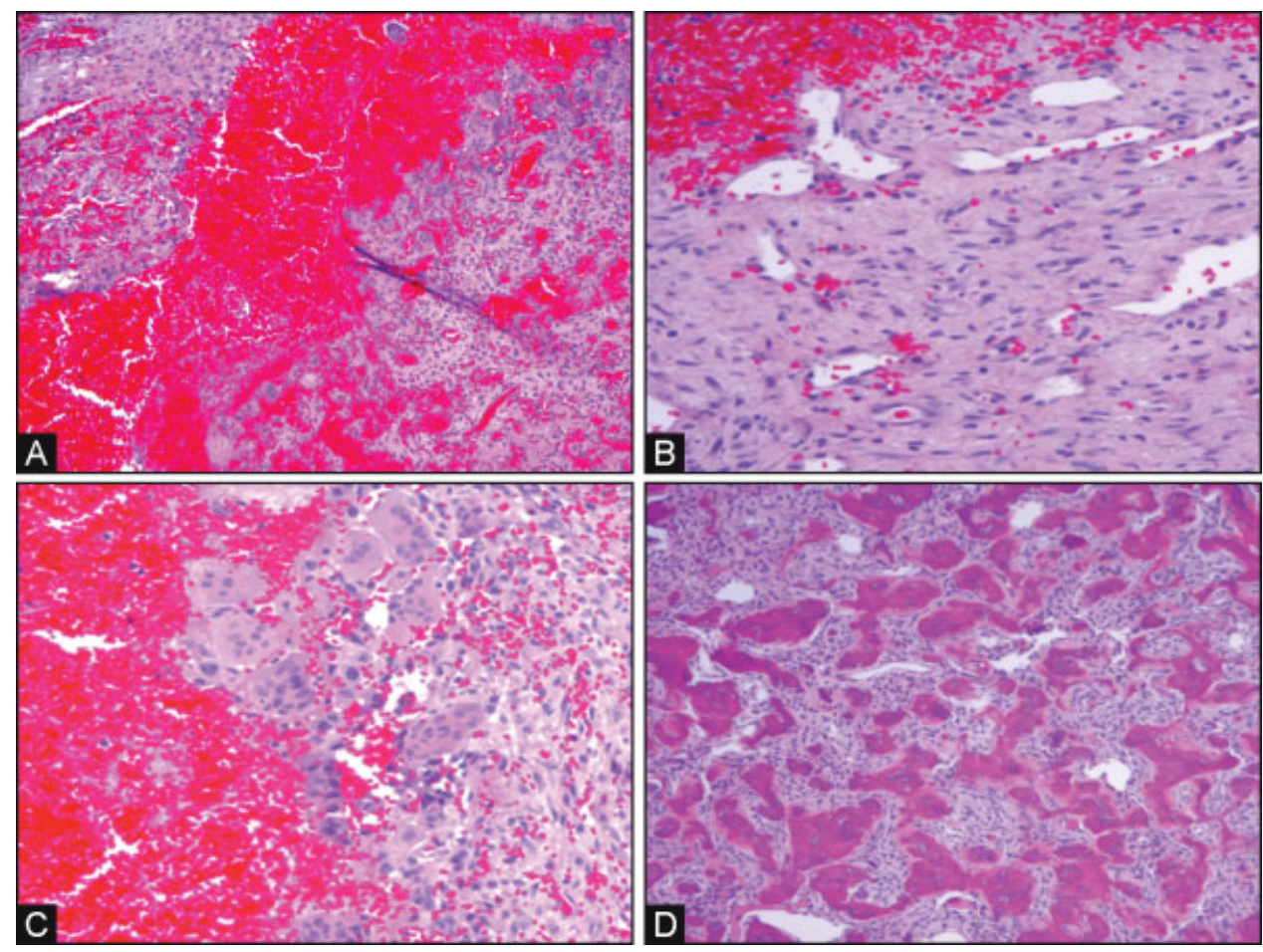

Fig. 4 (A) Low-power view, variable size blood-filled spaces divided by fibrous septae. (B) Higher power view, loose fibrous tissue containing multiple capillaries and monotonous population of plump fibroblasts. (C) Small group of osteoclast-like giant cells. (D) Background of benign fibroosseous proliferation (fibrous dysplasia versus ossifying fibroma). 
central giant cell granuloma were positive for ERs. The authors submit that this may have been a contributing factor in the lesion's rapid growth in pregnancy. Mintz et $\mathrm{al}^{6}$ described a patient with Albright syndrome and polyostotic fibrous dysplasia. During pregnancy, she went on to develop $A B C s$ within severe preexisting fibrous dysplasia in the humerus and acromion. The authors ascribed the development of the $\mathrm{ABCs}$ to hemodynamic and hormonal factors related to pregnancy. Two other $A B C$ cases associated with pregnancy, one of the ethmoid and one of the ileum, were reported, but neither was associated with documented rapid growth or development in pregnancy. ${ }^{7,8}$

\section{Discussion}

ABCs are uncommon lesions, accounting for 1 to $2 \%$ of all primary bone tumors. ${ }^{9}$ In their review, Mankin et $\mathrm{al}^{2}$ reported on $150 \mathrm{ABC}$ cases; mean age at presentation was 18 years, with females slightly more commonly affected. ${ }^{2}$ Lesions involving the skull are rare, comprising only 3 to $6 \%$ of all ABCs. ${ }^{3}$ ABCs have been reported to involve both the neurocranium (ethmoidal and/or sphenoidal, ${ }^{10-18}$ temporal, ${ }^{19-30}$ occipital, ${ }^{21,31-35}$ parietal, ${ }^{36,37}$ frontal, ${ }^{12,38-41}$ ) and viscerocranium (mandible, ${ }^{42}$ maxilla, ${ }^{43}$ and zygoma ${ }^{44}$ ).

Clinically, presentation depends on location. Lesions of the convexity usually present with localized swelling that may be painful or painless. ${ }^{45}$ Neurologic deficits are seldom present. Lesions involving the skull base are more likely to present with focal neurologic deficits. These can include anosmia, ${ }^{10,12}$ visual deficits, ${ }^{12,13,17,46}$ facial numbness, ${ }^{30}$ ocular motility deficits and diplopia, ${ }^{18,40}$ hearing loss, ${ }^{19,23,30}$ facial weakness, ${ }^{23,24,30}$ jugular foramen syndrome, ${ }^{47}$ and ataxia. ${ }^{33}$ ABCs may also present with symptoms and signs of elevated intracranial pressure, ${ }^{21,23,48}$ spontaneous intracranial hemorrhage, ${ }^{20,49}$ seizure, ${ }^{29,50}$ obstructive hydrocephalus, ${ }^{34}$ proptosis, ${ }^{10,14,16,17,40}$ epistaxis and nasal obstruction, ${ }^{11,12,15,17}$ otalgia, ${ }^{30}$ otitis media, ${ }^{24}$ and ear mass. ${ }^{27}$

Computed tomography (CT) findings include widening of diploic spaces, osseous expansion, narrowing of vascular and neural foramina, ground-glass opacity, and contrast enhancement. ${ }^{31}$ Fluid levels are present on CT in $35 \%$ of cases, with increased attenuation of the dependent level. ${ }^{40}$

Magnetic resonance imaging (MRI) is more likely than CT to show fluid levels, particularly on T1-weighted images. ${ }^{40}$ Although fluid levels are characteristic of ABCs, they may be observed in other lesions of the head and neck including cystic hygroma, soft tissue cavernous hemangioma, and simple bone cyst. ${ }^{51}$ Other MRI findings include multiple internal septations, a $\mathrm{T} 1$ and $\mathrm{T} 2$ hypointense rim demarcating the lesion from surrounding structures, and, on T1-weighted images, multiple internal lobulations with varying intensities $^{18}$ due to blood degradation products of differing ages. ${ }^{40} \mathrm{~A}$ soap bubble appearance may also be appreciated, due to the presence of diverticula, small cysts projected from larger cysts. $^{40}$

Cerebral angiography may show a significant tumor blush, usually on injection of the external carotid. The center of the lesion tends to be avascular; the periphery is highly vascularized.
Alternatively, the lesion may not demonstrate any blush but only displacement of the surrounding normal vessels. ${ }^{52}$

Pathogenesis of ABCs is somewhat controversial. They are often classified as primary and secondary, with primary lesions appearing in isolation and secondary lesions appearing in the setting of another antecedent osseous lesion or as a result of trauma. The most common such antecedent lesion is giant cell tumor. Other lesions include chondroblastoma, osteoblastoma, osteosarcoma, nonossifying fibroma, fibromyxoma, and fibrous dysplasia. ${ }^{46}$ Alternatively, it has been postulated that ABCs always arise as a secondary phenomenon in an antecedent lesion. The antecedent lesion undergoes involutional change, "initiates an intraosseous arteriovenous malformation and thereby creates, via hemodynamic forces, a secondary reaction of bone, which we know as an aneurysmal bone cyst." 53 An antecedent lesion can be identified histopathologically in about a third of $A B C s$, and it is possible that in cases in which no lesion is identified, it has been completely obliterated by the $A B C{ }^{54}$

In terms of pathology diagnosis, it can be important to differentiate primary from secondary ABCs. Many primary ABCs have a $\mathrm{t}(16 ; 17)(\mathrm{q} 22 ; \mathrm{p} 13)$ translocation. ${ }^{43}$ This translocation leads to a fusion of the cadherin 11 gene $(C D H 11)$ with ubiquitin specific peptidase 6/Tre-2 (USP6) gene. Other known fusion partners for USP6 are TRAP150, ZNF9, OMD, and COL1A1. ${ }^{41}$ This translocation is present only in fibroblasts and not seen in inflammatory cells, endothelial cells, metaplastic bone-associated osteoblasts, and multinucleated osteoclast-like giant cells. Secondary $A B C s$ arising in the background of another proliferative process (as in this case) do not show this particular translocation. ${ }^{1}$ There are other less frequent translocations (e.g., $\mathrm{t}(\mathrm{X} ; 9)(\mathrm{q} 26 ; \mathrm{q} 32)$ ) that can be seen in some ABCs. ${ }^{28}$

Another clinically important entity in the differential diagnosis is telangiectatic osteosarcoma. Low-power microscopic appearance is similar to an ABC, but telangiectatic osteosarcoma is a high-grade sarcoma and usually shows frank anaplasia at high power. Giant cell reparative granuloma, giant cell tumor, chondroblastoma, osteoblastoma, and combination of unicameral solitary bone cyst with post fracture changes are other more benign entities in the differential diagnosis of primary ABC. ${ }^{14}$ Overall, immunohistochemistry is not helpful in the diagnosis of $A B C$. Fibroblasts are positive for vimentin. Cytokeratins, EMA, MDM2, and CDK4 are negative.

Gross total resection is the treatment of choice for cranial $\mathrm{ABC}^{52}$ This may be more difficult to achieve when the lesion is large or when it involves the cranial base. Preoperative endovascular embolization is a useful adjunct if the tumor is highly vascular. Embolization is rarely used as a stand-alone treatment for lesions that are not surgically accessible. ${ }^{55}$ Radiotherapy has been used in some cases, but due to high recurrence rates (>30\%) and risk of sarcomatous degeneration, this treatment is reserved for unresectable or recurrent lesions ${ }^{3}$ and very seldom used. Gross total resection is generally curative, whereas subtotal resection or curettage has a recurrence rate of up to $50 \%{ }^{3}$

In the case we present, it is quite possible that the lesion exhibited rapid growth in pregnancy. Prior to her becoming 
pregnant, the patient experienced maxillary fullness and sinus pain. However, significant and rapidly progressive new symptoms arose during pregnancy including visual loss, proptosis, decreased ocular motility, and epistaxis. The tumor specimen was negative for ER and PR; therefore these hormones of pregnancy are unlikely to have played a role in rapid growth. However, increased hematopoiesis, increased cortisol, and increased HPL in pregnancy may have contributed to rapid growth of this patient's $A B C$.

\section{Conclusion}

ABCs of the skull are rare. They may exhibit rapid growth in pregnancy, although the reasons for this are not well known. This possibility should be taken into consideration when providing preconception counseling for patients with known ABCs, particularly of the skull base. Clinical presentation depends on location, and lesions can often be identified preoperatively based on characteristic imaging findings. Gross total resection is the treatment modality of choice. Familiarity with skull base techniques is essential to resect lesions safely and completely arising in these locations.

\section{Acknowledgments}

The authors thank Shirley McCartney, PhD, and Andy Rekito, MS, for editorial assistance and figure preparation, respectively.

\section{References}

1 Jaffe H, Lichtenstein L. Solitary unicameral bone cyst with emphasis on the roentgen pictures, the pathological appearance and the pathogenesis. Arch Surg 1942;44:1004-1025

2 Mankin HJ, Hornicek FJ, Ortiz-Cruz E, Villafuerte J, Gebhardt MC. Aneurysmal bone cyst: a review of 150 patients. J Clin Oncol 2005; 23(27):6756-6762

3 Guida F, Rapanà A, Conti C, Cagliari E, Civelli F, Trincia G. Cranial aneurysmal bone cyst: a diagnostic problem. With a review of the literature. Childs Nerv Syst 2001;17(4-5):297-301

4 Cataltepe O, Inci S, Ozcan OE, Sağlam S, Erbengi A. Aneurysmal bone cyst of the frontal bone. Surg Neurol 1990;33(6):391-394

5 Westbury SK, Eley KA, Athanasou N, Anand R, Watt-Smith SR. Giant cell granuloma with aneurysmal bone cyst change within the mandible during pregnancy: a management dilemma. J Oral Maxillofac Surg 2011;69(4):1108-1113

6 Mintz MC, Dalinka MK, Schmidt R. Aneurysmal bone cyst arising in fibrous dysplasia during pregnancy. Radiology 1987;165(2): 549-550

7 Baker HL, Papsidero MJ, Batsakis JG, Krause CJ. Aneurysmal bone cyst of the ethmoid. Head Neck Surg 1982;5(2):177-180

8 Issa AA, Amr SS, Swaiss AM. Aneurysmal bone cyst of the ilium associated with pregnancy. Eur J Obstet Gynecol Reprod Biol 1986; 23(3-4):243-248

9 Leithner A, Windhager R, Lang S, Haas OA, Kainberger F, Kotz R. Aneurysmal bone cyst. A population based epidemiologic study and literature review. Clin Orthop Relat Res 1999;(363):176-179

10 Hrishikesh KA, Narlawar RS, Deasi SB, Aniruddha K, Maheshwari S. Case report: Aneurysmal bone cyst of the ethmoid bone. Br J Radiol 2002;75(899):916-918
11 Fikri M, Meziane M, El Hassani MR, et al. Aneurysmal cyst of ethmoid bone: a case report [in French]. Arch Pediatr 2013;20(3): 292-295

12 Nadkarni T, Goel A, Desai K, Aiyer P, Shenoy A. Massive aneurysmal bone cyst of the anterior cranial fossa floor-case report. Neurol Med Chir (Tokyo) 2001;41(12):615-619

13 Yee RD, Cogan DG, Thorp TR, Schut L. Optic nerve compression due to aneurysmal bone cyst. Arch Ophthalmol 1977;95(12): 2176-2179

14 Ozdamar Y, Acaroglu G, Kazanci B, Saka C, Kazanci B. Aneurysmal bone cyst of the ethmoid presenting with proptosis and epiphora. Orbit 2010;29(3):149-151

15 Goyal A, Rastogi S, Singh PP, Sharma S. Aneurysmal bone cyst at the base of the skull. Ear Nose Throat J 2012;91(5):E7-E9

16 Hunter JV, Yokoyama C, Moseley IF, Wright JE. Aneurysmal bone cyst of the sphenoid with orbital involvement. Br J Ophthalmol 1990;74(8):505-508

17 Terkawi AS, Al-Qahtani KH, Baksh E, Soualmi L, Mohamed Ael-B, Sabbagh AJ. Fibrous dysplasia and aneurysmal bone cyst of the skull base presenting with blindness: a report of a rare locally aggressive example. Head Neck Oncol 2011;3:15

18 Tamimi AF, Nimri C, Huseini M, Abu-Elrub M, Kharazi K, Tamimi I Aneurysmal bone cyst of the sphenoid bone as an intracranial and orbital space-occupying lesion. Pediatr Neurosurg 2005;41(5): 280-282

19 Sawin PD, Muhonen MG, Sato Y, Smith RJ. Aneurysmal bone cyst of the temporal bone presenting as hearing loss in a child. Int J Pediatr Otorhinolaryngol 1995;33(3):275-284

20 Keuskamp PA, Horoupian DS, Fein JM. Aneurysmal bone cyst of the temporal bone presenting as a spontaneous intracerebral hemorrhage: case report. Neurosurgery 1980;7(2):166-170

21 Chateil JF, Dousset V, Meyer P, et al. Cranial aneurysmal bone cysts presenting with raised intracranial pressure: report of two cases. Neuroradiology 1997;39(7):490-494

22 Tuna H, Karatas A, Yilmaz ER, Yagmurlu B, Erekul S. Aneurysmal bone cyst of the temporal bone: case report. Surg Neurol 2003; 60(6):571-574

23 Cakirer S, Basak M, Celebi I, Kabukcuoglu F, Erdem Y. Aneurysmal bone cyst of the temporal bone. Curr Probl Diagn Radiol 2003; 32(4):169-175

24 Sabatini PR, Horenstein MG, Oliveri CV, Gacek RR. Aneurysmal bone cyst of the temporal bone associated with reversible hemifacial paralysis. Am J Otolaryngol 2005;26(4):261-264

25 Lippman CR, Jallo GI, Feghali JG, Jimenez E, Epstein F. Aneurysmal bone cyst of the temporal bone. Pediatr Neurosurg 1999;31(4): 219-223

26 Haddad GF, Hambali F, Mufarrij A, Nassar A, Haddad FS. Concomitant fibrous dysplasia and aneurysmal bone cyst of the skull base. Case report and review of the literature. Pediatr Neurosurg 1998; 28(3):147-153

27 Park AH, Phillips J, Forte V. Aneurysmal bone cyst of the temporal bone. Otolaryngol Head Neck Surg 1999;120(4):606-610

28 Buxi TB, Sud S, Vohra R, Sud A, Singh S. Aneurysmal bone cyst of the temporal bone. Australas Radiol 2004;48(2):251-255

29 Stapleton CJ, Walcott BP, Linskey KR, Kahle KT, Nahed BV, Asaad WF. Temporal bone chondroblastoma with secondary aneurysmal bone cyst presenting as an intracranial mass with clinical seizure activity. J Clin Neurosci 2011;18(6):857-860

30 Sayama CM, MacDonald JD. Aneurysmal bone cyst of the petrous bone: case presentation and review of the literature. Pediatr Neurosurg 2010;46(4):308-312

31 Itshayek E, Spector S, Gomori M, Segal R. Fibrous dysplasia in combination with aneurysmal bone cyst of the occipital bone and the clivus: case report and review of the literature. Neurosurgery 2002;51(3):815-817; discussion 817-818

32 Petro ML, Lancon JA. Occipital aneurysmal bone cyst. Pediatr Neurosurg 2001;34(1):45-46 
33 Han X, Dong Y, Sun K, Lu Y. A huge occipital osteoblastoma accompanied with aneurysmal bone cyst in the posterior cranial fossa. Clin Neurol Neurosurg 2008;110(3):282-285

34 Curtis BR, Petteys RJ, Rossi CT, Keating RF, Magge SN. Large occipital aneurysmal bone cyst causing obstructive hydrocephalus in a pediatric patient. J Neurosurg Pediatr 2012;10(6):482-485

35 Genizi J, Srugo I, Attias D, et al. Giant pediatric aneurysmal bone cysts of the occipital bone: case report and review of the literature. Pediatr Neurol 2011;45(1):42-44

36 Branch CL Jr, Challa VR, Kelly DL Jr. Aneurysmal bone cyst with fibrous dysplasia of the parietal bone. Report of two cases. J Neurosurg 1986;64(2):331-335

37 Lee JW, Kim JH, Han SH, Kang HI. Fibrous dysplasia with aneurysmal bone cyst presenting as painful solitary skull lesion. J Korean Neurosurg Soc 2010;48(6):551-554

38 Lin WC, Wu HT, Wei CJ, Chang CY. Aneurysmal bone cyst arising from fibrous dysplasia of the frontal bone (2004:2b). Eur Radiol 2004;14(5):930-932

39 Schonauer C, Tessitore E, Schonauer M. Aneurysmal bone cyst of the frontal bone in a soccer player. Acta Neurochir (Wien) 2000; 142(10):1165-1166

40 Senol U, Karaali K, Akyüz M, Gelen T, Tuncer R, Lüleci E. Aneurysmal bone cyst of the orbit. AJNR Am J Neuroradiol 2002;23(2): 319-321

41 Abuzayed B, Dashti R, Turk O, Kaynar MY. Aneurysmal frontal bone cyst in a child with history of acute lymphoblastic leukemia: a case of rare location and history. J Pediatr Hematol Oncol 2010;32(1):e1-e3

42 Zadik Y, Aktaş A, Drucker S, Nitzan DW. Aneurysmal bone cyst of mandibular condyle: a case report and review of the literature. J Craniomaxillofac Surg 2012;40(8):e243-e248

43 Lee HM, Cho KS, Choi KU, Roh HJ. Aggressive aneurysmal bone cyst of the maxilla confused with telangiectatic osteosarcoma. Auris Nasus Larynx 2012;39(3):337-340
44 Tai YT, Yen PC, Chou EK. Aneurysm bone cyst presented as a zygomatic mass after facial trauma. J Trauma 2011;70(4):E74

45 Kumar R, Mukherjee KK. Aneurysmal bone cysts of the skull: report of three cases. Br J Neurosurg 1999;13(1):82-84

46 Salmasi V, Blitz AM, Ishii M, Gallia GL. Expanded endonasal endoscopic approach for resection of a large skull base aneurysmal bone cyst in a pediatric patient with extensive cranial fibrous dysplasia. Childs Nerv Syst 2011;27(4):649-656

47 Aghaghazvini L, Sedighi N, Karami P, Yeganeh O. Skull base aneurysmal bone cyst presented with foramen jugular syndrome and multi-osseous involvement. Iran J Radiol 2012; 9(3): $157-160$

48 Ito H, Kizu O, Yamada K, Nishimura T. Secondary aneurysmal bone cyst derived from a giant-cell tumour of the skull base. Neuroradiology 2003;45(9):616-617

49 Mattei TA, Mattei JA, Ramina R, Aguiar PH. Fibrous dysplasia in combination with aneurysmal bone cyst presenting as a subarachnoid haemorrhage. Neurol Sci 2005;26(3):178-181

50 Gopalakrishnan CV, Rao BR, Nair S, Radhakrishnan VV, Kesavadas C. Intracranial intradural aneurysmal bone cyst: a unique case. Pediatr Neurosurg 2009;45(4):317-320

51 Catalano P, Fang-Hui E, Som PM. Fluid-fluid levels in benign neurogenic tumors. AJNR Am J Neuroradiol 1997;18(2):385-387

52 Sheikh BY. Cranial aneurysmal bone cyst "with special emphasis on endovascular management.". Acta Neurochir (Wien) 1999; 141(6):601-610; discussion 610-611

53 Biesecker JL, Marcove RC, Huvos AG, Miké V. Aneurysmal bone cysts. A clinicopathologic study of 66 cases. Cancer 1970;26(3):615-625

54 Kransdorf MJ, Sweet DE. Aneurysmal bone cyst: concept, controversy, clinical presentation, and imaging. AJR Am J Roentgenol 1995;164(3):573-580

55 Ikeda H, Niizuma H, Yoshimoto T. Aneurysmal bone cyst of the skull. Surg Neurol 1986;25(2):145-148 